DOI: 10.20472/IAC.2017.034.028

\author{
MARLIN KILLEN \\ DREXEL UNIVERSITY, United States
}

\title{
IMPACT OF AN INNOVATIVE MODEL FOR DEVELOPING STANDARDS FOR ONLINE COURSES IN HIGHER EDUCATION
}

\begin{abstract}
:
Online education has become an important part of the landscape of higher education. Indeed, approximately $80 \%$ of colleges and universities offer online courses as part of their standard schedule of courses. As online course offerings have become commonplace, accrediting agencies have come to include examination of institutional criteria for setting standards and measuring the quality of those offerings as part of routine site evaluations. Concerns about which standards should be used and how to meet the scrutiny of accreditation agencies have prompted institutions to explore options for pre-formatted checklists of online course quality.

Despite a broad range of possible products and services, many institutions are challenged to find instruments that both meet the critical need of establishing guidelines for online course design, and allow sufficient adaptability to meet unique institutional and programmatic needs and characteristics. In addition, rigid, standardized instruments have prompted faculty to question whether the instruments exert too much influence, restrain their academic freedom, and restrict their choices for methods of instruction.

This presentation will report on an innovative model utilized at one institution to address the challenges of creating its own standards for online course design quality and the outcomes of that effort.
\end{abstract}

\section{Keywords:}

Innovation, Online, Education

JEL Classification: 123,129 